PUBLIC HEALTH
1) $1^{\text {st }}$ Gynecology Department, Iuliu Hatieganu University of Medicine and Pharmacy, Cluj-Napoca, Romania

2) IMOGEN Research Institute, ClujNapoca, Romania

3) "Dr. Gheorghe Marinescu" Municipal Hospital, Tarnaveni, Romania

4) Health Department, Environmental Health Center, Cluj-Napoca, Romania

5) Faculty of Environmental Science and Engineering, Babes-Bolyai University, Cluj-Napoca, Romania

6) Departments of Environmental Health Sciences and Epidemiology and Biostatistics, University at Albany, State University of New York, Rensselaer, New York, United States

DOI: 10.15386/cjmed-984

Manuscript received: 15.02 .2018

Received in revised form: 23.10.2018 Accepted: 12.11.2018

Address for correspondence: iulianeamtu@ehc.ro

\title{
Birth defects in Tarnaveni area, Romania - preliminary study results
}

Razvan Mihaileanu ${ }^{1,2,3}$, Iulia Adina Neamtiu ${ }^{2,4,5}$, Michael Bloom ${ }^{6}$, Florin Stamatian ${ }^{1,2}$

\begin{abstract}
Background and aims. In the development of any human body, defects may occur, resulting in the occurrence of congenital malformations, also referred to as birth defects. The aim of this preliminary study was to assess the prevalence of birth defects registered during a period of 5 years in Tarnaveni area. As Tarnaveni is located in close proximity to a former chemical plant, a recognized hazardous waste site, we conducted this pilot study to assess the prevalence of birth defects, in order to evaluate the need for a more comprehensive investigation of a potential relation between the exposure to toxic metals contaminating the environmental media as a result of the past industrial activities, and the prevalence of the birth defects in this area.
\end{abstract}

Methods. We abstracted birth information (gestational age at delivery (GA), birth weight (BW), birth length (BL), head circumference (HC), and major structural birth defects), from medical records at "Dr. Gheorghe Marinescu“ Tarnaveni Municipal Hospital, of the 2010-2014 period. We expressed BW as Z-scores relative to expected mean values at each gestational age for a reference population, calculated the ponderal index, and determined the 5 years birth defects prevalence among live births during the study interval.

Results. The 5 years $(2010-2014)$ prevalence of birth defects, was 3.3\% (95\% confidence interval $(\mathrm{CI}): 2.47,4.09)$. There were $\mathrm{n}=163(8.7 \%)$ preterm deliveries (less than 37 weeks of gestation at delivery), mean birth weight was $3108.3 \mathrm{~g}$ (standard deviation $(\mathrm{SD})=517.1)$, ranging from $450-4600 \mathrm{~g}$, and $\mathrm{n}=187(10 \%)$ were low birth weight (LBW) (less than $2500 \mathrm{~g}$ ). The ponderal index was $2.2 \mathrm{~g} / \mathrm{cm}^{3}$ on average $(\mathrm{SD}=0.5)$, with range $1.2-20.7 \mathrm{~g} / \mathrm{cm}^{3}$.

Conclusions. While preliminary, our data show a 5 years (2010-2014) prevalence of major structural birth defects among newborns from Tarnaveni area of $3.3 \%$. These pilot results indicate the need for a more comprehensive investigation of a potential relation between the exposure to toxic metals contaminating the environmental media as a result of the past industrial activities and the prevalence of the birth defects in Tarnaveni area.

Keywords: hazardous waste site, heavy metals, birth defects, low birth weight, Tarnaveni

\section{Introduction}

Birth defects, also known as congenital anomalies, congenital disorders or congenital defects have been defined as anomalies of the structure and/or function of an organ and/or a system in the body, detectable prenatally (by ultrasound examination), at birth or during infancy [1]. Their prevalence at a European level, reported for 2003-2007 period, by European Surveillance of Congenital Anomalies (EUROCAT) was 2.39 per 100 births [2]. However, EUROCAT reported 2010-2014 birth defects prevalence of 2.5 per 100 births for Ukraine, $1.35-2.25$ per 100 births for Poland, and 2.25-2.75 per 100 births for Austria [3]. Yet, for Romania, Zavate et al. [4] reported a birth defects prevalence of 1.3 per 100 live births during the 20032007 period, lower than the reported prevalence at the European level. The most frequent severe birth defects worldwide, are congenital heart defects, neural tube defects and Down syndrome.

While the etiology of most birth defects is unknown, genetic factors (e.g. single gene defects, chromosomal disorders, multifactorial inheritance) and environmental factors (e.g. environmental chemicals with teratogenic effects, high doses of radiations, iodine and/or folic acid diet deficiency, and biological environmental agents such as rubella virus, among others) are likely to cause birth 
defects [5]. Also, advanced maternal age is a risk factor for non-disjunction related abnormalities in fetal development (chromosomal abnormalities, such as Down syndrome) [6].

Previous reports linked higher risks for birth defects with proximity to hazardous waste sites [7-9] and to heavy metals exposure $[10,11]$. Thus, arsenic $(\mathrm{As})$, lead $(\mathrm{Pb})$ and manganese $(\mathrm{Mn})$ exposure via contaminated environmental media has been linked to higher frequencies of birth defects, such as congenital heart defects and neural tube defects in human populations [12-14].

Birth defects are an important cause of infant death, worldwide. In the European Region, the World Health Organization (WHO) estimated that up to $25 \%$ of neonatal deaths are attributable to congenital anomalies [6]. Also, congenital disorders are an important issue for the health services, requesting multidisciplinary medical care and significant financial resources [1].

The aim of this preliminary study was to assess the prevalence of birth defects registered during the 5 years period from 2010-2014, in Tarnaveni area. Tarnaveni is located in close proximity to a former chemical plant and is recognized as a hazardous waste site with high levels of heavy metal contamination [15]. Thus, we conducted this pilot study to assess the prevalence of birth defects, in order to evaluate the need for a future comprehensive study of a potential relation between the toxic metals exposure via contaminated environmental media and the prevalence of the birth defects in this area.

\section{Methods}

Study area

Tarnaveni is a town in Transylvania (Mures County), located on the Tarnava Mica River, with 22,075 inhabitants [16]. A chemical plant located close to the town operated until 2007, and produced chemical products containing hexavalent chromium $\left(\mathrm{Cr}^{6+}\right)$. Millions of tons of chemical waste, including $\mathrm{Cr}^{6+}$ and other heavy metals remained on the former industrial platform, in close proximity to the town and river [17].

Birth outcomes/defects data collection and analysis

We abstracted de-identified birth information from the birth registries between 2010-2014, including GA, $\mathrm{BW}, \mathrm{BL}$, and HC. We collected information on structural birth defects at delivery from clinical observation sheets corresponding to each delivery and ultrasound examination results. All records were kept at the Gynecology and Obstetrics Department of the "Dr. Gheorghe Marinescu" Municipal Hospital in Tarnaveni. Birth defects were defined as anomalies of structure and/or organ/system function diagnosed by a physician before delivery using ultrasound, or after delivery, but prior to hospital discharge.

We calculated a 5 years prevalence of birth defects among the total number of live births during that period of time (as number of birth defects x 100/number of live births). We did not include $n=14$ cases of systolic murmur in the calculation of the 5 years prevalence, as these cases did not need further therapeutic intervention and so, were more likely to reflect a delayed fetal growth trajectory rather than a true defect. However, for comparison, we also calculated the 5 years prevalence including the 14 cases of systolic murmur. We used Excel 2016 (Microsoft Co., Redmond, Washington, USA) to calculate the 5 years prevalence of birth defects and $95 \% \mathrm{CI}$, overall and according to maternal age, and also, for plotting the percent of diagnosed birth defect among the live births in Tarnaveni, between 20102014 (categorized at organ and system level).

We considered GA as a continuous variable and dichotomized at less than 37 weeks, to indicate preterm delivery [18]. We calculated the Z-score for BW (BW-Z), using reference values published by Kramer et al. [19], as $(\mathrm{BWs}-\mathrm{BWr}) / \mathrm{SDr}$, where $\mathrm{BWs}=\mathrm{BW}$ of our population sample; $\mathrm{BWr}=$ the mean values of $\mathrm{BW}$ at each gestational age for the reference population; $\mathrm{SDr}=$ standard deviation for the $\mathrm{BW}$ of the reference population). We defined small for gestational age (SGA) infants, an indicator of intrauterine growth restriction, as birth weights less than the $10^{\text {th }}$ percentile of the expected value from the reference population [18]. We also dichotomized $\mathrm{BW}$, to indicate

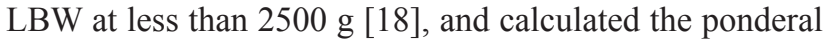
index (PI), an indicator of growth proportionality, as BW (g) $x$ 100/BL ${ }^{3}(\mathrm{~cm})$.

We used Stata v12 (StataCorp LP, College Station, TX, USA) to generate descriptive statistics, including mean, $\mathrm{SD}$, median, $25^{\text {th }}$ and $75^{\text {th }}$ percentiles, and the range of values for continuous variables (GA, BW, BL, HC, PI, $\mathrm{BW}-\mathrm{Z}$ ) and to generate frequency tables for categorical variables $(\mathrm{n}, \%)$. We defined statistical significance as $\mathrm{p}$ $<0.05$ for a 2 -tailed hypothesis test.

\section{Results}

Table I describes the distribution of birth outcomes during 2010-2014 among Tarnaveni area newborns.

Table II shows the type of birth defects diagnosed in newborns from Tarnaveni area during 2010-2014, and the prevalence of birth defects among live births in this area. The 5 year birth defects prevalence was $3.3 \%$ overall excluding $\mathrm{n}=14$ cases of systolic murmur, and $4.03 \%$ overall, when including the 14 cases of systolic murmur. Most birth defects were isolated anomalies affecting an organ (e.g. anomalies of the genital organs - cryptorchidism) or system (e.g. nervous system - congenital hydrocephalus), but there were also several $(n=3)$ multiple organ and system abnormalities.

In Table III, we show the frequency and prevalence of birth defects by mother's age in our study area, with $95 \%$ CI. The prevalence of total birth defects increased with mother's age, with the highest prevalence among mothers aged $35-40$ years $(7 \%$; $95 \%$ CI $2.58,11.37)$.

The birth defects diagnosed in newborns from Tarnaveni area, between 2010-2014, included congenital defects of the cardiac chambers and connections, chromosomal 
abnormalities, defects of the digestive system, nervous system, urinary and genital organs, and endocrine glands, ear structural defects, defects of the musculoskeletal system, and multiple birth defects (Figure 1). The birth defects of the musculoskeletal system comprised the largest proportion (36.1\%) of total diagnosed birth defects, closely followed by the of the cardiac chambers and connections defects $(22.9 \%)$, and then, by defects of the urinary and genital organs $(18.0 \%)$.

Table I. Distribution of birth outcomes in Tarnaveni area, in 2010-2014 period.

\begin{tabular}{|c|c|c|c|c|c|c|c|c|}
\hline Outcome & $\mathbf{N}$ & Mean (\%) & SD & Min. & $25^{\text {th }}$ percentile & Median & $75^{\text {th }}$ percentile & Max. \\
\hline Gestational age (weeks) & 1871 & 38.8 & 1.9 & 23 & 38 & 39 & 40 & 43 \\
\hline Caesarean birth & 322 & $17.2 \%$ & - & - & - & - & - & - \\
\hline Preterm delivery (less than 37 weeks) & 163 & $8.7 \%$ & - & - & - & - & - & - \\
\hline $\mathrm{BW}(\mathrm{g})$ & 1871 & 3108.6 & 517.2 & 450 & 2800 & 3100 & 3450 & 4600 \\
\hline LBW (less than $2500 \mathrm{~g}$ ) & 187 & $10 \%$ & & & & & & \\
\hline BW-Z & $1863 \mathrm{a}$ & -0.5 & 0.8 & -3.4 & -1.1 & -0.6 & 0.02 & 3.2 \\
\hline SGA & $189 \mathrm{a}$ & $10 \%$ & & & & & & \\
\hline $\mathrm{BL}(\mathrm{cm})$ & 1871 & 51.9 & 2.6 & 21 & 51 & 52 & 53 & 60 \\
\hline PI $\left(\mathrm{g} / \mathrm{cm}^{3}\right)$ & 1871 & 2.2 & 0.5 & 1.2 & 2.1 & 2.2 & 2.3 & 20.7 \\
\hline $\mathrm{HC}(\mathrm{cm})$ & 1871 & 33.1 & 1.7 & 20 & 32 & 33 & 34 & 52 \\
\hline Male baby & 982 & $52.5 \%$ & & & & & & \\
\hline
\end{tabular}

BL, birth length; BW, birth weight; LBW, low birth weight; BW-Z, birth weight Z score; HC, head circumference; SGA, small for gestational age; PI, ponderal index; N, frequency; mean, arithmetic average; SD, standard deviation; Max., maximum reported value; Min., minimum reported value; median, $50^{\text {th }}$ percentile.

a calculated only for singleton live births

Table II. Prevalence (\%) of birth defects relative to the total number of live births (N), in Tarnaveni area, in 2010-2014 period.
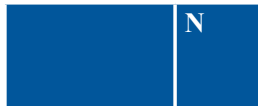

Live births

Birth defects $61^{\mathrm{b}}$
5 years birth defects prevalence (\%) and $95 \% \mathrm{CI}$

Diagnosed birth defects

\section{Dit} prevalence $(\%)$ and $95 \% \mathrm{CI}$

Cardiac chambers and connections defects, unspecified 14

Musculoskeletal system defects

congenital clubfoot

congenital dislocation of the hip, unilateral

diastasis rectus abdominis

polydactyly, unspecified

syndactyly of toes (fused toes)

unspecified congenital defect of the left hand

unspecified congenital bone and joint defect

omphalocele

bilateral inguinal hernia

Endocrine glands defects

congenital hypothyroidism

Nervous system defects

congenital hydrocephalus

congenital generalized hypertonia

congenital generalized hypotonia

unspecified congenital neurological disease

Congenital ear defect, unspecified

Urinary and genital organs defects

bilateral undescended testis

cryptorchidism

hypospadias

congenital ovarian cyst

unspecified congenital defect of the kidney

Digestive system defects

anorectal atresia

Chromosomal abnormalities

Down syndrome

Multiple birth defects, unspecified
Frequency of the

reported birth defects

(n cases)

\section{4}

22 (total)

11

1

3

1

2

1

1

1

5 (total)

1

2

1

1

11 (total)

6

2

1

1 (total)

1

3 (total)

3

$\mathrm{N}$, total reported number of live births

a newborns with Apgar score $=0$ were excluded (only live births were included in the analysis;

$\mathrm{b}$ excluded $\mathrm{n}=14$ infants with minor cardiac defects clinically expressed as systolic murmur

Note: the 5 year prevalence of birth defects increases to $4.03 \%$ (95\% CI: $3.14,4.92)$ when including those $n=14$ infants. 
Table III. Frequency (n cases) and prevalence (\%) of birth defects by mothers' age (years), in Tarnaveni area, in 2010-2014 period

\begin{tabular}{l|c|c|c|c|c|}
\hline Diagnosed birth defects & $\mathbf{1 3 - 2 0}$ & $\mathbf{2 0 - 3 0}$ & $\mathbf{3 0 - 3 5}$ & $\mathbf{3 5 - 4 0}$ & above 40 \\
\hline Defects of cardiac chambers and connections & 6 & 4 & 3 & 1 & 0 \\
Chromosomal abnormalities & 1 & 0 & 1 & 1 & 0 \\
Defects of digestive system & 0 & 1 & 0 & 0 & 0 \\
Ear malformation & 0 & 1 & 0 & 0 & 0 \\
Endocrine glands malformation & 1 & 0 & 0 & 0 & 0 \\
Multiple defects & 2 & 0 & 0 & 1 & 0 \\
Musculoskeletal system defects & 3 & 12 & 4 & 3 & 0 \\
Nervous system defects & 0 & 2 & 1 & 1 & 1 \\
Urinary and genital organs defects & 1 & 6 & 2 & 2 & 0 \\
Total defects & $\mathbf{1 4}$ & $\mathbf{2 6}$ & $\mathbf{1 1}$ & $\mathbf{9}$ & $\mathbf{1}$ \\
Total live births & $\mathbf{3 6 7}$ & $\mathbf{1 0 0 2}$ & $\mathbf{3 4 8}$ & $\mathbf{1 2 9}$ & $\mathbf{2 5}$ \\
Prevalence (\%) of total birth defects among & 3.8 & 2.6 & 3.2 & 7.0 & 4.0 \\
total live birth, by mother's age and (95\% CI) & $(1.85,5.77)$ & $(1.61,3.58)$ & $(1.32,5.00)$ & $(2.58,11.37)$ & $(-3.68,11.68)$
\end{tabular}

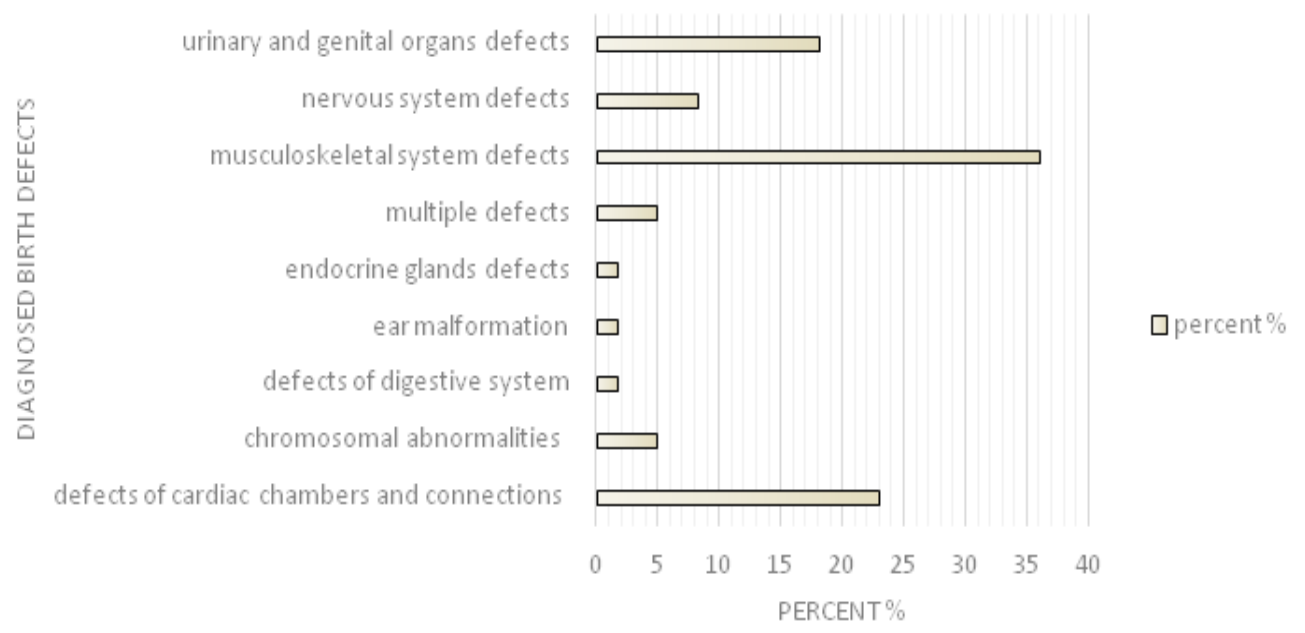

Figure 1. Proportion of total congenital defects by organs and system, in Tarnaveni area, in the 2010-2014 period

\section{Discussion}

In this preliminary study we report a prevalence of $3.3 \%$ birth defects, among Tarnaveni area newborns, for the 5 years period from 2010-2014. This value is higher than the $1.3 \%$ prevalence reported for Romania overall, during 2003-2007 [4]. But yet, we should not rule out the possibility that this difference to be only apparent, due to the differences in detection/survival, and the small population sample size in our pilot study may also, account, in part, for this difference. We also showed that, $9 \%$ of deliveries in Tarnaveni area between 2010 and 2014, were preterm deliveries, $10 \%$ were LBW, and $10 \%$ were SGA.
The birth defects prevalence rate in Tarnaveni area was higher than that reported for all of Cluj County during 2003-2007, 1.33\% [4], Tarnaveni's birth defect prevalence also eclipsed the $0.69 \%$ prevalence reported for the entire 6 counties North West region of Romania (i.e., Bihor, Bistrita-Nasaud, Cluj, Maramures, Satu Mare, and Salaj counties) during the same time period (2003-2007) [4]. We can speculate that the differences might be due in part to time trends, as the Tarnaveni data are from 2010-2014, and due to differences in the ascertainment, diagnosis, and reporting of birth defects. Preconception care and socio-economic differences between Cluj County and the 
Romanian North West region as compared to Tarnaveni area, are also likely to be important. However, the higher birth defects prevalence in Tarnaveni area might also be attributed in part to reproductive toxicity associated with the presence of the hazardous waste site in close proximity to the town, which has contaminated the environmental media in the surroundings with heavy metals.

We conducted this investigation to assess the prevalence of birth defects in this area of Romania, as birth defects are a leading cause of infant mortality worldwide. In Romania, infant mortality due to birth defects was 21.2 per 10,000 live births in 2012, a decrease from 40.2 per 10,000 live births in 1990 [20]. The etiology remains unknown in approximately half of birth defects [21], while the other half is attributed to genetic factors and to complex geneenvironment interactions [22]. Previous studies that looked into the etiology of birth outcomes and morphological abnormalities, have indicated that environmental contaminants may be associated with a significant increase in the prevalence of birth defects [23,24]. The exposure to a toxic chemical compound might cause a birth defect (congenital malformation) via a mechanism of preconceptional mutation (including chromosomal abnormalities) or via a mechanism of teratogenic action after conception [23]. Brent and Beckman [25,26] estimated that $10 \%$ of major birth defects are caused by teratogenic chemicals, while $37 \%$ result from the interaction between genetic and environmental factors. More recent estimates suggest that as much as $80 \%$ of developmental diseases in children are due to gene-environment interactions [27]. Still, many birth defects caused by chromosomal abnormalities are incompatible with survival and affected fetuses are spontaneously aborted early in gestation [28,29]. Thus, identifying modifiable risk factors for the risk of congenital defects is an urgent public health priority [30].

Previous studies link environmental heavy metal exposures to birth defects. Higher risks for congenital cardiovascular defects (odds ratio $(\mathrm{OR})=2.2 ; 95 \% \mathrm{CI}$ : $1.3,3.9)$ were reported for children born from mothers living in close proximity to contaminated sites, who were exposed to heavy metals and cyanides during pregnancy [31]. A study conducted in North Carolina [14], reported an association between higher levels of exposure to $\mathrm{Mn}$ (prevalence ratio (PR): 1.6; 95\% CI: 1.1, 2.5) and Pb (PR: $1.7 ; 95 \%$ CI: $0.9,3.3$ ) via drinking water and an increased prevalence of heart defects. In another study, higher levels of $\mathrm{Mn}$ in the placenta were linked to a 4 -fold $(95 \% \mathrm{CI}$ : $1.23,14.79)$ higher risk of neural tube defects and a 7 -fold (95\% CI: 1.52, 39.64) higher risk of spina bifida [32]. Elevated maternal blood levels of $\mathrm{Pb}$, As, cadmium (Cd) and copper $(\mathrm{Cu})$ were risk factors for neural tube defects in a study conducted in Turkey [33]. A study by Vinceti et al., indicated a higher risk for cardiovascular defects, oral clefts, and musculoskeletal defects associated with exposure to $\mathrm{Pb}$ in northern Italy [34]. A study conducted in
California, showed that women living in the surroundings of a factory using $\mathrm{Cr}^{6+}$, had an increased risk for pregnancy loss, and the risk for birth defects, such as genitourinary, eye, ear, face, neck, cleft defects and chromosomal anomalies in offspring, was also elevated [35]. A recent study by Ou et al. [36], evaluating the relationship between heavy metal levels measured in maternal blood $(\mathrm{Pb}, \mathrm{Cd}$, $\mathrm{Cr}, \mathrm{Cu}$, mercury $(\mathrm{Hg})$, and selenium (Se)) and congenital heart defects in offspring, found that high maternal blood $\mathrm{Pb}(\mathrm{OR}=12.09,95 \% \mathrm{CI}: 2.81,51.97)$ was associated with heart defects in offspring, suggesting that exposure to levels at the current biological limit for protecting human health $(10 \mu \mathrm{g} / \mathrm{dL})$, may still harm an unborn child.

In the light of scientific literature on this topic, we conducted our pilot study to assess the prevalence of birth defects in Tarnaveni, an area highly contaminated with heavy metals, for comparison with the reported birth defects prevalence values for other areas of Romania and at the national level. The higher prevalence of the birth defects in Tarnaveni area that we show in this pilot study, indicates the need for a more comprehensive investigation of risk factors for adverse birth outcomes and birth defects, in particular from maternal exposure to the toxic metals contaminating the local environment. To investigate the role of exposure to hazardous substances in the environmental media as risk factors for birth defects in the population living in this area, we plan to collect soil, vegetable, and biological samples as part of a future analysis.

This pilot study is a preliminary component of a larger ongoing research project, in which we will analyze heavy metal concentrations in soil, vegetables, and maternal blood specimens in a population sample from Tarnaveni, to evaluate the relationships with the prevalence of birth defects and adverse birth outcomes. The successful completion of our extended study will provide scientific data that are currently missing in this area, concerning the exposure to heavy metals in the environmental media and the potential related effects on fetal in utero development. Also, these data might be used to design interventions to reduce the prevalence of birth defects in Tarnaveni, by offering regulators and legislators a valid scientific foundation upon which to make critical public health decisions and to initiate management and risk communication programs for protecting the health of susceptible populations.

To the best of our knowledge, this is the first study that has analyzed data on birth defects in Tarnaveni area historically polluted with $\mathrm{Cr}^{6+}$, a highly toxic contaminant for which there is a body of scientific evidences suggesting that gestational exposure may be associated with low birth weight and internal and skeletal malformations, and is reporting a higher prevalence of birth defects in this area than in other regions and at national level, raising serious concerns on a possible association of this higher prevalence with the environmental exposure to $\mathrm{Cr}^{6+}$. 


\section{Conclusions}

While preliminary, our data showed a 5 years (20102014) prevalence rate of birth defects higher in Tarnaveni area than for other North West Romanian Counties and for Romania overall. We found the highest prevalence for the birth defects of the musculoskeletal system, and also, as expected, the prevalence of birth defects increased with mother's age. We have an ongoing investigation in this area (soil, vegetables and biological samples collection and analysis) to evaluate potential associations between exposure to toxic metals in the residential areas surrounding the site of the former chemical plant in Tarnaveni, and birth defects prevalence.

\section{Acknowledgements}

The financial support for this research was provided by Iuliu Hatieganu University of Medicine and Pharmacy, Cluj-Napoca (grant no. 7690/71/15.04.2016). The funders had no role in study design, data collection and analysis, decision to publish, or preparation of the manuscript.

\section{References}

1. Corsello G, Giuffrè M. Congenital malformations. J Matern Fetal Neonatal Med. 2012;25 Suppl 1:25-29.

2. Dolk H, Loane M, Garne E. The prevalence of congenital anomalies in Europe. Adv Exp Med Biol. 2010;686:349-364.

3. European Surveillance of Congenital Anomalies (EUROCAT).

4. Zavate L, Râjnoveanu A, Zavate A. Study of prevalence and birth defects types in the children from two development regions of Romania: NW and SW. Acta Medica Transilvanica. 2012;2:162-164.

5. Kalter H. Teratology in the 20th century: environmental causes of congenital malformations in humans and how they were established. Neurotoxicol Teratol. 2003;25:131-282.

6. World Health Organization (WHO). Sixty-third world health assembly - Birth defects. 2010.

7. Kuehn CM, Mueller BA, Checkoway H, Williams M. Risk of malformations associated with residential proximity to hazardous waste sites in Washington State. Environ Res. 2007;103:405-412.

8. Mattiello A, Chiodini P, Bianco E, Forgione N, Flammia I, Gallo $\mathrm{C}$, et al. Health effects associated with the disposal of solid waste in landfills and incinerators in populations living in surrounding areas: a systematic review. Int J Public Health. 2013;58:725-735. 9. Santoro M, Minichilli F, Pierini A, Astolfi G, Bisceglia L, Carbone P, et al. Congenital Anomalies in Contaminated Sites: A Multisite Study in Italy. Int J Environ Res Public Health. 2017;14(3). pii: E292.

10. Wigle DT, Arbuckle TE, Turner MC, Bérubé A, Yang Q, Liu S, et al. Epidemiologic evidence of relationships between reproductive and child health outcomes and environmental chemical contaminants. J Toxicol Environ Health B Crit Rev. 2008;11:373-517.

11. Dolk H. Epidemiologic approaches to identifying environmental causes of birth defects. Am J Med Genet C Semin Med Genet. 2004;125C:4-11.

12. Langlois PH, Brender JD, Suarez L, Zhan FB, Mistry JH, Scheuerle A, et al. Maternal residential proximity to waste sites and industrial facilities and conotruncal heart defects in offspring.
Paediatr Perinat Epidemiol. 2009;23:321-331.

13. Brender JD, Suarez L, Felkner M, Gilani Z, Stinchcomb D, Moody K, et al. Maternal exposure to arsenic, cadmium, lead, and mercury and neural tube defects in offspring. Environ Res. 2006;101:132-139.

14. Sanders AP, Desrosiers TA, Warren JL, Herring AH, Enright $\mathrm{D}$, Olshan AF, et al. Association between arsenic, cadmium, manganese, and lead levels in private wells and birth defects prevalence in North Carolina: a semi-ecologic study. BMC Public Health. 2014;14:955.

15. Suciu I, Cosma C, Todică M, Bolboacă SD, Jäntschi L. Analysis of soil heavy metal pollution and pattern in Central Transylvania. Int J Mol Sci. 2008;9:434-453.

16. Romanian National Institute of Statistics - Mureș County Department of Statistics. Census final results 2011.

17. Lupei T, Matei M, Laslo L, Nicolescu AM. Study on the environmental pollution risks induced by the former Chemical Plant in Târnăveni, Mureş County. ECOTERRA - J Environ Res Protect. 2014;11:32-39.

18. WHO: recommended definitions, terminology and format for statistical tables related to the perinatal period and use of a new certificate for cause of perinatal deaths. Modifications recommended by FIGO as amended October 14, 1976. Acta Obstet Gynecol Scand. 1977;56:247-253.

19. Kramer MS, Platt RW, Wen SW, Joseph KS, Allen A, Abrahamowicz M, et al. A new and improved population-based Canadian reference for birth weight for gestational age. Pediatrics. 2001;108:E35.

20. Romanian National Institute of Statistics. Life Expectancy. 2013.

22. Dörner G. Environment- and gene-dependent human ontogenesis, sociogenesis and phylogenesis (eco-geno-ontosocio-phylogenesis). Neuro Endocrinol Lett. 2004;25:164-168.

23. Dolk H, Vrijheid M. The impact of environmental pollution on congenital anomalies. Br Med Bull. 2003;68:25-45.

24. Buczyńska A, Tarkowski S. Environmental exposure and birth outcomes. Int J Occup Med Environ Health. 2005;18:225-232.

25. Brent RL, Beckman DA. Environmental teratogens. Bull N Y Acad Med. 1990;66:123-163.

26. Brent RL. Environmental causes of human congenital malformations: the pediatrician's role in dealing with these complex clinical problems caused by a multiplicity of environmental and genetic factors. Pediatrics. 2004;113(4 Suppl):957-968.

27. Mattison DR. Environmental exposures and development. Curr Opin Pediatr. 2010; 22:208-218.

28. Byrne J, Warburton D, Kline J, Blanc W, Stein Z. Morphology of early fetal deaths and their chromosomal characteristics. Teratology. 1985;32:297-315.

29. Ujházy E, Mach M, Navarová J, Dubovický M. Teratology on the crossroads: historical aspects and modern approaches. Neuro Endocrinol Lett. 2012;33:304-313.

30. Feldkamp ML, Carey JC, Byrne JLB, Krikov S, Botto LD. Etiology and clinical presentation of birth defects: population based study. BMJ. 2017;357:j2249.

31. Shaw GM, Schulman J, Frisch JD, Cummins SK, Harris JA. Congenital malformations and birthweight in areas with potential environmental contamination. Arch Environ Health. 1992;47:147-154.

32. Liu J, Jin L, Zhang L, Li Z, Wang L, Ye R, et al. Placental concentrations of manganese and the risk of fetal neural tube defects. J Trace Elem Med Biol. 2013;27:322-325. 
33. Demir N, Başaranoğlu M, Huyut Z, Değer İ, Karaman K, Şekeroğlu MR, et al. The relationship between mother and infant plasma trace element and heavy metal levels and the risk of neural tube defect in infants. J Matern Fetal Neonatal Med. 2017;1-8. [Epub ahead of print]

34. Vinceti M, Rovesti S, Bergomi M, Calzolari E, Candela S, Campagna A, et al. Risk of birth defects in a population exposed to environmental lead pollution. Sci Total Environ. 2001;278:23-30.
35. Remy LL, Byers V, Clay T. Reproductive outcomes after non-occupational exposure to hexavalent chromium, Willits California, 1983-2014. Environ Health. 2017 Mar 6;16:18.

36. Ou Y, Bloom MS, Nie Z, Han F, Mai J, Chen J, et al. Associations between toxic and essential trace elements in maternal blood and fetal congenital heart defects. Environ Int. 2017; 106:127-134. 